\title{
Control of weld composition when arc welding high strength aluminium alloys using multiple filler wires
}

\section{G. Pickin*, S. W. Williams, P. Prangnell, C. Derry and M. Lunt}

\begin{abstract}
An experimental method of controlling weld composition when welding Al2024 has been explored. Utilising the tandem process and a cold wire feed unit, two and three commercially available filler wires were mixed in a single weld pool to control composition. Thermodynamic modelling was used to provide optimum weld compositions for the eradication of solidification cracking. Validation showed that by controlling the principal elements, not only was cracking eliminated, the mechanical properties of the weld could be varied. In particular, a composition was identified, which offered adequate joint strength and ductility. Exceeding this composition resulted in a corresponding increase in weld hardness at the expense of joint ductility.
\end{abstract}

Keywords: Tandem welding, Filler wire development, High strength aluminium alloys

\section{Introduction}

Aluminium alloys of the 5000 series Al-Mg (5083) and the 7000 series $\mathrm{Al}-\mathrm{Mg}-\mathrm{Zn}$ (7017 and 7039) have been used for many years for armour applications. Ternary high strength aerospace 2000 series alloys (typically Al$\mathrm{Cu}-\mathrm{Mg}$ and $\mathrm{Al}-\mathrm{Cu}-\mathrm{Li}$ ) exhibit comparable, if not appreciable increases in strength, and as such, are possible candidate alloys for the future construction of armoured fighting vehicles.

For volume armoured fighting vehicle production, friction stir welding is an emerging process offering advantages over traditional arc welding processes and as such will likely be the primary employed joining technology. ${ }^{1-4}$ However, arc welding processes (typically GMAW) do offer advantages; in particular, their single sided operation allows greater flexibility in joint design and the relatively low capital cost is notable. Both processes therefore should be considered for volume production. When arc welding aluminium alloys, in general, hot cracking is a concern. ${ }^{5}$ In particular, solidification cracking ${ }^{6,7}$ in the weld bead and liquation cracking in the partially melted zone $(\mathrm{PMZ})^{8-11}$ can result. Both of these phenomena can be controlled by correct selection of filler wire for the base material to be welded. Solidification cracking results from a large weld pool freezing range and is primarily intergranular in nature, occurring along grain boundaries due to stresses induced during terminal solidification. By selecting a filler wire that offers the lowest freezing range of the final eutectic reactions after dilution with the base material, sufficient strength in the weld bead can be realised to prevent fissuring during solidification. Studies into liquation

Welding Engineering Research Centre, Cranfield University, Cranfield, UK *Corresponding author, email c.g.pickin @cranfield.ac.uk cracking mechanisms have utilised thermodynamic modelling to show that cracking in the PMZ can be eradicated by controlling the rate of weld pool solidification by varying the alloy content of the weld metal. ${ }^{12}$ Further studies have shown that maintaining the weld solute content above the solidification cracking range by varying the weld composition eradicated both cracking modes in a variety of alloy systems. ${ }^{13}$

Correct filler wire selection is therefore a key prerequisite for suppression of hot cracking. However, when welding ternary alloy systems selection is compromised as available fillers are typically binary based and when utilised to weld ternary alloys, cracking frequently occurs due to the resulting wide freezing range. Developing matched filler wires is, however, an expensive and subjective process. In these respects, a simple and cost effective experimental method of generating different weld compositions would vastly expand the application potential of newer alloy systems. The objective of this research is to show how utilising innovative mixed wire welding processes the composition and mechanical properties of the weld bead can be varied and controlled.

\section{Experimental}

Aluminium alloy Al-2024 T351 (12.7 mm) was used as the base material. Mixing experiments investigated the principal elements copper $(\mathrm{Cu})$ and magnesium $(\mathrm{Mg})$.

For tandem welding, this was achieved utilising commercially available binary based $\mathrm{Al}-\mathrm{Cu}(1.6 \mathrm{~mm}$ diameter) and $\mathrm{Al}-\mathrm{Mg}$ filler wires (1.2 $\mathrm{mm}$ diameter).

When using three filler wires, $\mathrm{Cu}$ addition was enabled using filler $\mathrm{CuSi} 3(0.8 \mathrm{~mm}$ diameter). Although this wire contains silicon $(\mathrm{Si})$ when mixed with larger diameter aluminium filler wires, the composition is low enough for the formation of brittle intermetallic $\mathrm{Mg}_{3} \mathrm{Si}$ to be avoided. ${ }^{14}$ Commercially available $\mathrm{Al}-\mathrm{Mg}$ filler wires 
and 'pure' aluminium filler (both $1.6 \mathrm{~mm}$ diameter) were used for controlling $\mathrm{Mg}$ content in this configuration.

Specification compositions (wt- $\%$ ) and material density $\rho$ of the employed fillers and base material are detailed in Table 1.

Single element compositions $E \%$ input, using both two and three filler wires, were determined using equation (1), where $V_{\text {filler* }}$ is the filler wire volume derived from the diameter of the wire and the feed rate, $E_{\text {filler* }}$ is the nominal element composition and $\rho_{\text {filler* }}$ is the density of the filler material. $V_{\text {weld }}$ is the calculated total volume of the deposited filler wires and $\rho_{\text {weld }}$ is the density of the deposited weld, this being taken as the density of Al-2024 as an approximation. When only two filler wires are employed, the numerators for filler ${ }_{3}$ can be discounted

$$
\begin{aligned}
E \% \text { input }= & V_{\text {filler } 1} \rho_{\text {filler } 1} E_{\text {filler } 1}+V_{\text {filler } 2} \rho_{\text {filler } 2} E_{\text {filler2 }} \\
& +\left(V_{\text {filler } 3} \rho_{\text {filler } 3} E_{\text {filler } 3}\right) / V_{\text {weld }} \rho_{\text {weld }}
\end{aligned}
$$

Equation (1) does not, however, take into account weld dilution. Element composition of the weld $E \%$ at a given dilution ratio was determined using equation (2) where $A_{\mathrm{b}}$ is the area of weld penetration and $A_{\mathrm{f}}$ is the area of weld reinforcement.

$$
\begin{aligned}
E^{0} \%_{\text {weld }}= & (E \% \text { in base metal })\left[A_{\mathrm{b}} /\left(A_{\mathrm{b}}+A_{\mathrm{f}}\right)\right] \\
& +\left(E^{\%} \% \text { in filler }\right)\left[A_{\mathrm{f}} /\left(A_{\mathrm{b}}+A_{\mathrm{f}}\right)\right]
\end{aligned}
$$

Actual weld composition was measured using energy dispersive X-ray (EDX) analysis on cross-sections taken from the weld. The average of four spectra $(1 \times 1 \mathrm{~mm})$ were calculated based upon the areas of measurement detailed in Fig. 1.

For assessing solidification crack tendency multi pass fillet welds (six passes) were deposited on constrained test pieces of $250 \times 100 \mathrm{~mm}$ which were bolted into a steel fixture utilising three M10 bolts per side. Weld interpass temperature was maintained at ambient. After each weld pass, a visual crack inspection was performed. A total of three test samples were produced for each set of input parameters.

Microhardness (Vickers) testing was conducted on bead on plate welds. Tensile tests were conducted on dog bone samples machined to a gauge length of $100 \mathrm{~mm}$, width of $12 \mathrm{~mm}$ and a reduced thickness of $6 \mathrm{~mm}$. All samples were naturally aged for a minimum of 30 days before testing.

Tandem welding equipment consisted of two Fronius TPS 5000 power sources and a single tandem push pull torch unit. A Lincoln Electric GTAW cold wire feed unit was used for delivery of the third filler wire.

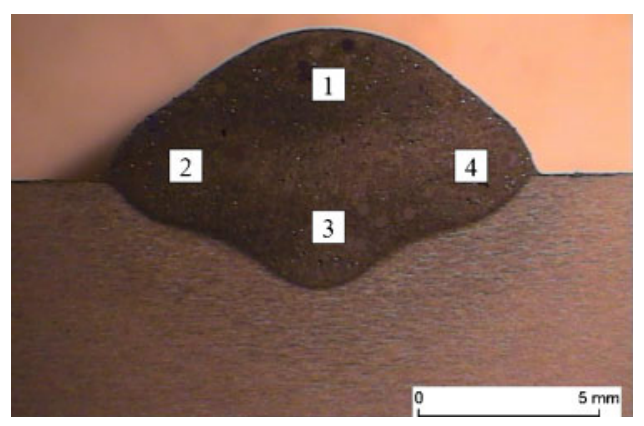

1 EDX areas of measurement $(1 \times 1 \mathrm{~mm}$ spectra)

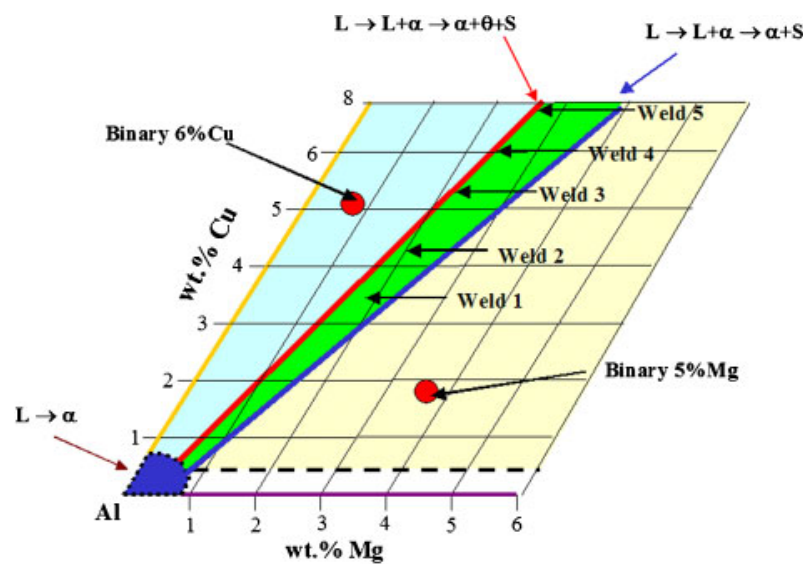

2 Summary weld compositions based on thermodynamic modelling

\section{Methodology \\ Modelling approach}

The solidification behaviour of ternary $\mathrm{Al}-\mathrm{Cu}-\mathrm{Mg}$ type alloys has previously been investigated. ${ }^{15,16}$ This work examined the weld freezing behaviour for varying compositions of the principal elements $\mathrm{Cu}$ and $\mathrm{Mg}$. By controlling the ratio of these two elements, a range of compositions could be modelled resulting in the freezing path terminating with the single ternary eutectic reaction, $\mathrm{L} \rightarrow \alpha+\theta+\mathrm{S}$. This gave the minimum freezing range for the final $10 \%$ liquid in the $\mathrm{Al}-\mathrm{Mg}-\mathrm{Cu}$ ternary system and the ideal composition for suppressing cracking, this being represented by the solid red line in Fig. 2. The green area represents further compositions up to the saddle point (blue line) where the reaction temperatures increase sharply. Within this region, the solidus is controlled by the final eutectic reaction at $502-507^{\circ} \mathrm{C}$. The approximate weld target compositions for the five welds examined as

\begin{tabular}{|c|c|c|c|c|c|c|c|c|c|c|}
\hline Material & $\rho, \mathrm{g} \mathrm{cm}^{-3}$ & $\mathrm{Mn}$ & Si & $\mathrm{Ti}$ & $\mathrm{Mg}$ & $\mathrm{Zn}$ & $\mathrm{Cr}$ & $\mathrm{Fe}$ & $\mathrm{Cu}$ & $\mathrm{Al}$ \\
\hline Alloy 2024 & $2 \cdot 78$ & & 0.5 & $0 \cdot 20$ & $1 \cdot 2-1 \cdot 8$ & $0 \cdot 2$ & $0 \cdot 1$ & 0.5 & $3 \cdot 8-4 \cdot 9$ & Bal. \\
\hline Filler 2319 & $2 \cdot 77$ & $0 \cdot 3$ & $0 \cdot 2$ & $0 \cdot 15$ & 0.02 & $0 \cdot 1$ & $\ldots$ & $0 \cdot 3$ & $5 \cdot 8-6 \cdot 3$ & Bal. \\
\hline Filler 5554 & $2 \cdot 69$ & 0.5 & $0 \cdot 2$ & $\ldots$ & $2 \cdot 4-3 \cdot 0$ & $0 \cdot 25$ & 0.05 & $0 \cdot 4$ & $0 \cdot 10$ & Bal. \\
\hline Filler 5556 & $2 \cdot 66$ & $0 \cdot 1$ & 0.2 & $0 \cdot 20$ & $4 \cdot 7-5 \cdot 5$ & $0 \cdot 25$ & $0 \cdot 2$ & $0 \cdot 4$ & $0 \cdot 10$ & Bal. \\
\hline Filler 1050 & $2 \cdot 71$ & 0.05 & $0 \cdot 25$ & 0.05 & 0.05 & $\ldots$ & $\ldots$ & $0 \cdot 4$ & 0.05 & Bal. \\
\hline Filler CuSi & $8 \cdot 53$ & $1 \cdot 0$ & $3 \cdot 0$ & $\ldots$ & $\ldots$ & $0 \cdot 1$ & $\ldots$ & $\ldots$ & Bal. & $\ldots$ \\
\hline
\end{tabular}
part of this work are also shown. Crack susceptible compositions using the 2319 and 5556 binary filler wires

Table 1 Material specification values: composition (wt-\%) and density 

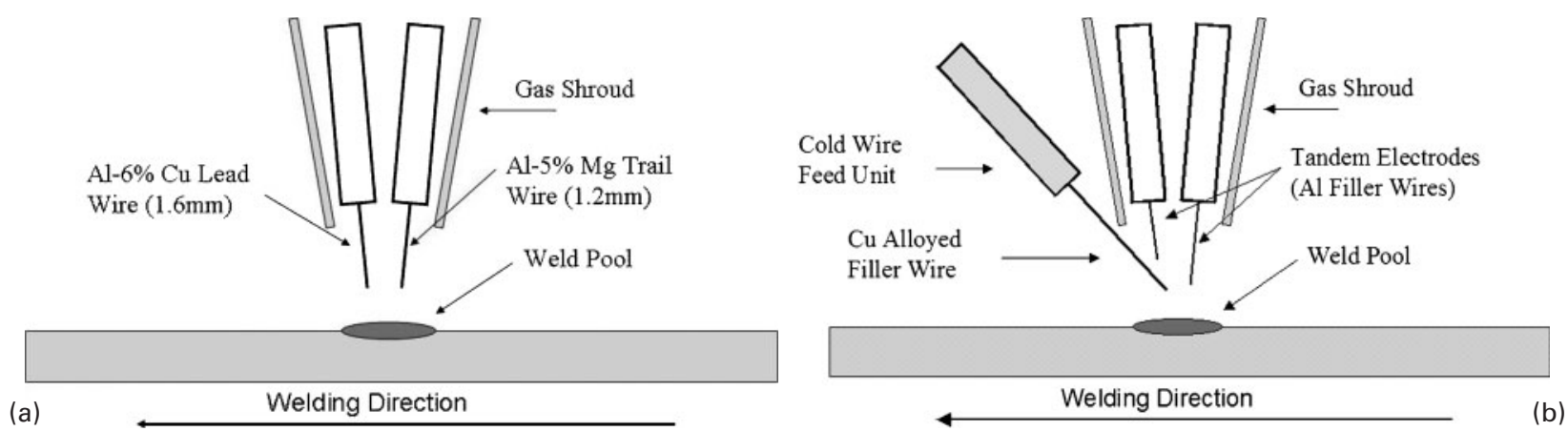

$3 a$ tandem mixed wire welding configuration and $b$ three-wire mixed welding configuration

(single wire welds) are included showing wide deviation from the optimum composition.

\section{Mixed wire welding}

Mixed wire welding systems were examined utilising two and three filler wires. The authors have previously shown that mixing different series aluminium binary filler wires in the tandem process can produce a controlled ternary composition. ${ }^{16}$ A typical configuration is shown in Fig $3 a$. This concept was further developed with the addition of a third filler wire shown in Fig $3 b$. Adopting this approach, the range of possible compositions was extended.

The third filler was cold fed, i.e. it was decoupled from the welding process and relied on the tandem arc generating sufficient heat to ensure melting and mixing in the weld pool. In the current example, the tandem process was used to control the weld $\mathrm{Mg}$ content utilising different series aluminium filler wires with the $\mathrm{Cu}$ content controlled by the cold wire feed unit.

\section{Results and discussion}

\section{Process optimisation}

While the tandem system exhibited good stability and weld pool mixing, the three-wire process required greater parameter optimisation. Insufficient mixing resulted when simply feeding the third filler wire into the weld pool. $\mathrm{A} \mathrm{Cu}$ rich band was evident in the weld bead which placed the remainder of the weld in a crack susceptible composition based on Fig. 2. Further trials were conducted where the placement of the third filler wire was varied in order that melting within the arc could be realised. Control of the arc voltage was required in order that the lead arc was directed below the third filler. Adopting this approach, sufficient heat was generated to ensure melting of the filler wire and droplets would be formed within the arc. This is shown in the high speed image sequence in Fig. 4. Mixing primarily occurred when the mass of the molten globule of $\mathrm{Cu}$ filler exceeded its surface tension strength and merged with the molten droplet of the lead filler wire. This was then detached via a combination of gravitational force and Lorentz force. Further mixing was ensured by the trail filler wire deposition. Deposited welds appeared visually stable with little spatter and uniform bead geometry. Deviation from this configuration, i.e. melting of the $\mathrm{Cu}$ filler directly within the tandem arc, resulted in process instability. In particular, ejection of $\mathrm{Cu}$ droplets (spatter) was evident.

\section{Weld composition}

Bead on plate welds were conducted using both processes with input parameters derived from equation (1). To ensure accuracy, average wire feedrates were
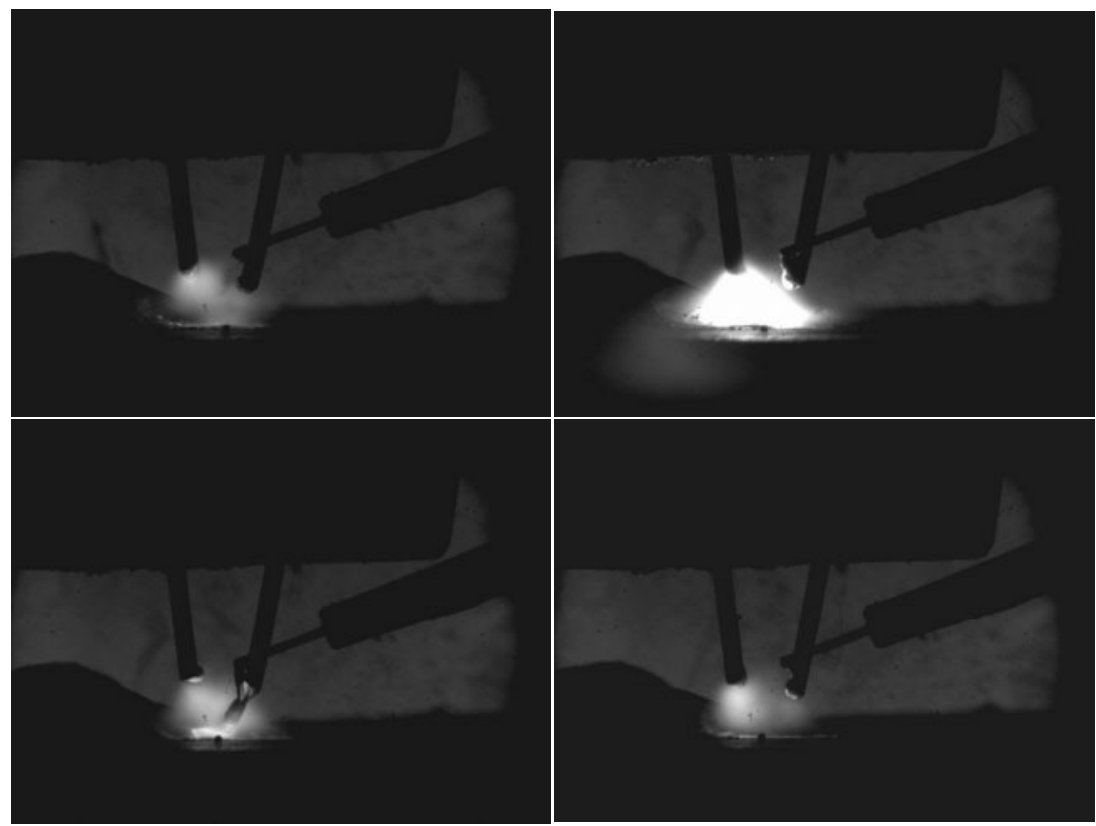

4 High speed images: three-wire welding process sequence showing optimum third wire placement 


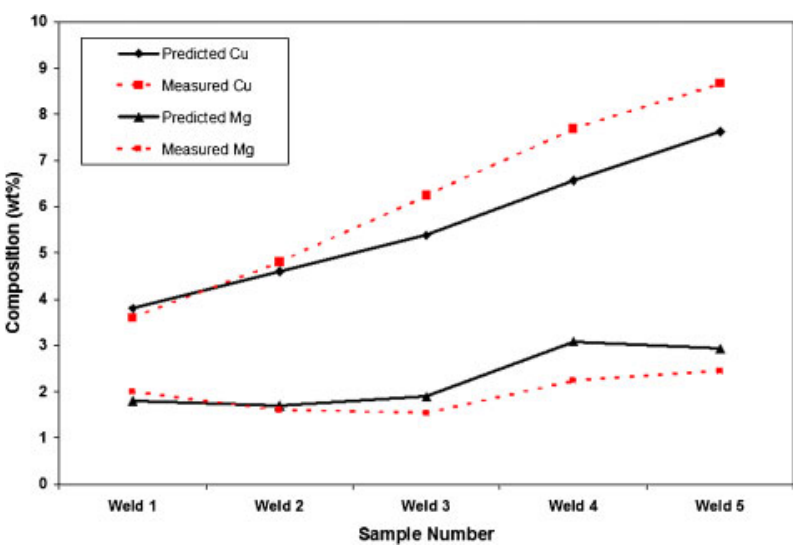

5 Element mixing: measured and predicted values

measured and the readings used to recalculate the input parameters (Table 2).

Cross-sections were then taken from each weld bead and the dilution ratio measured. Equation (2) was used to predict the final weld compositions. These were then compared with the average EDX measured values and are shown in Fig. 5.

Although some deviation is evident, this is partly attributed to average composition values of both base material and filler wires being used in the calculations, whereas relatively wide specification values are detailed in Table 1. Additionally, average wire feedrates and approximated density values were used which further influenced the calculated values. Analysis of the spread of measured values for each sample showed a mixing variation of approximately $\pm 5 \%$ when examining compositions deposited using binary fillers. For $\mathrm{Cu}$ addition using the third filler, mixing variation was in the region of $\pm 7 \%$. While greater system optimisation for both processes would result in greater accuracy, the predicted mixing trend is evident.

Crack tests were performed utilising the input parameters from Table 2. No cracking was evident for any weld composition. With the exception of weld 2 which has a composition similar to the base material, the other test samples will exhibit changes to their composition due to the effects of dilution with, initially the base material, then with each successive weld pass. However, when this variation is considered based on equation (2) and the measured values shown in Fig. 4, a controlled ratio of the principle elements results. Calculating for dilution ratios of $40-50 \%$ shows that although changes are evident between the first and final weld passes, composition still lies within the ideal mixing range in Fig. 2. The absence of cracks shows the requirement of maintaining a controlled ternary alloyed weld. This is further emphasised when considering the use of binary
Al-Mg fillers. Reference to Fig. $6 a$ shows a single wire weld deposited using the $5556(5 \mathrm{wt}-\% \mathrm{Mg})$ filler in isolation. Severe solidification cracking is evident with the result that the weld sequence could not be completed. This has previously been identified ${ }^{16}$ as being due to the formation of $\mathrm{T}$ phase and the resulting wide freezing range. Figure $6 b$ shows a multipass weld utilising the input parameters for weld 4 with no cracking being evident. Although this sample was produced using two $\mathrm{Al}-\mathrm{Mg}$ filler wires in the tandem process, alloying with $\mathrm{Cu}$ from the addition of the third filler resulted in a controlled ternary $\mathrm{Al}-\mathrm{Cu}-\mathrm{Mg}$ composition which suppressed cracking due to a narrower terminal freezing range.

\section{Composition properties}

Tensile testing was conducted as previously defined. Figure 7 shows the average ultimate tensile strength (UTS) results and corresponding sample extension, measured across the $100 \mathrm{~mm}$ gauge length for the range of compositions examined. Additionally joint efficiency $(\%)$ is included based upon the average UTS of the base material $(420 \mathrm{MPa})$. The results indicate the relationship between increased alloy content and mechanical properties. In particular, the compositions of welds 2 and 3 exhibit the highest UTS and extension, this declining with greater weld alloy content.

The relationship between weld hardness and ductility is presented in Fig. 8. A $15 \mathrm{~mm}$ extensometer was utilised which measured elongation only across the width of the weld and the adjacent PMZ. While increasing the weld alloy content resulted in an increase in weld hardness (weld 5 with a similar value to the base material, $150 \mathrm{HV}$ ), a clear relationship is shown between increased hardness and a reduction in ductility. Examination of the failure mode of each tested sample showed failure initiated in the PMZ. Further microhardness maps were conducted across the whole of the weldment. Figure 9 shows the comparative results for welds 2 and weld 5. Fluctuation in hardness is evident for a narrow band in the PMZ for each weld composition. Although this is not as pronounced for weld 2, it is notable that the hardness of this weld is similar to that of the PMZ and hence, any fluctuation is not readily apparent. Previous research ${ }^{17}$ examining the welding of binary 2219 $(6 \mathrm{wt}-\% \mathrm{Cu})$ has shown that a band of depleted $\mathrm{Cu}(\alpha)$ was found next to a $\mathrm{Cu}$ rich $\mathrm{GB}$ eutectic in this region. Microhardness maps showed that the $\mathrm{Cu}$ depleted zone was much softer that the $\mathrm{Cu}$ rich eutectic. This indicated that the PMZ solidified under conditions of severe liquation and that a soft brittle matrix resulted. When considering the solidification of Al-2024, the authors have previously identified the melting point of the base material to be in the region of $640^{\circ} \mathrm{C}$ with the ternary

Table 2 Measured wire feedrates and resulting calculated weld input composition (welds 1 and 2 employ $1.2 \mathrm{~mm}$ diameter 5556 wire)

\begin{tabular}{|c|c|c|c|c|c|c|c|}
\hline \multirow[b]{2}{*}{ Weld } & \multicolumn{3}{|c|}{ Tandem wires, $\mathrm{m} \mathrm{min}^{-1}$} & \multirow[b]{2}{*}{5556} & \multirow{2}{*}{$\begin{array}{l}\text { Third wire, } \mathrm{m} \mathrm{min}^{-1} \\
\text { CuSi3 }\end{array}$} & \multicolumn{2}{|c|}{ Input composition, wt- $\%$} \\
\hline & 5554 & 2319 & 1050 & & & $\mathrm{Mg}$ & $\mathrm{Cu}$ \\
\hline 1 & - & 6 & - & 8 & - & 2 & $3 \cdot 4$ \\
\hline 2 & - & 7 & - & 5 & - & $1 \cdot 4$ & $4 \cdot 3$ \\
\hline 3 & - & - & $5 \cdot 8$ & $5 \cdot 6$ & 0.98 & $2 \cdot 3$ & $6 \cdot 3$ \\
\hline 4 & $5 \cdot 8$ & - & - & $5 \cdot 8$ & $1 \cdot 20$ & $3 \cdot 7$ & $7 \cdot 5$ \\
\hline 5 & $5 \cdot 7$ & - & - & $5 \cdot 8$ & $1 \cdot 48$ & $3 \cdot 6$ & $9 \cdot 3$ \\
\hline
\end{tabular}




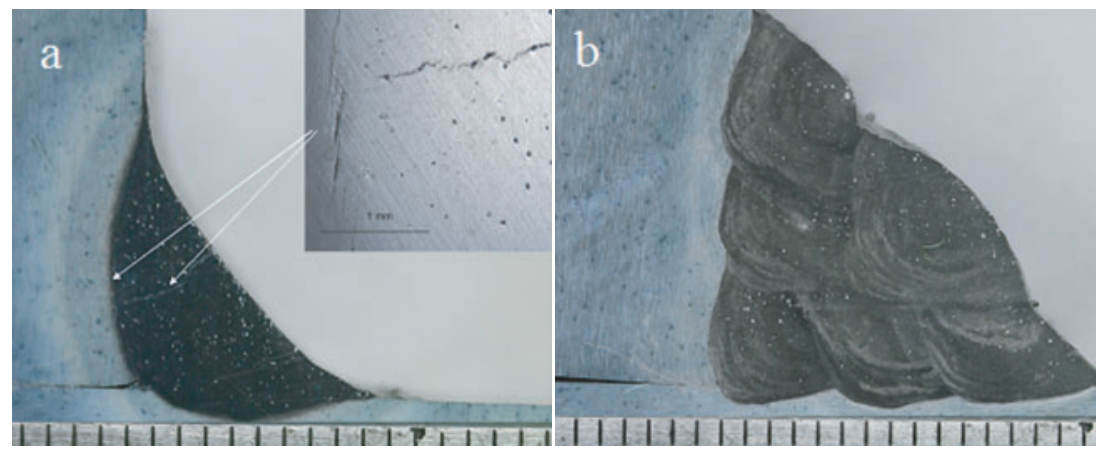

6 a single 5556 wire welds showing cracking and $b$ three-wire weld (weld 4) with no cracking

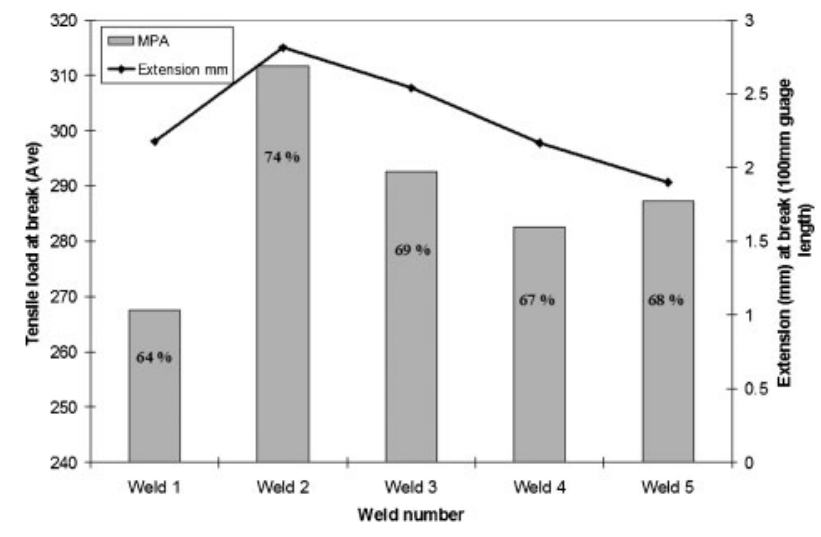

7 Comparative tensile properties

eutectic occurring around $500^{\circ} \mathrm{C} .{ }^{15,16}$ Clearly, formation of the PMZ must occur close to the melting temperature. Rapid heating during welding results in liquation and diffusion of both $\mathrm{Cu}$ and $\mathrm{Mg}$. On resolidification solute is rejected, forming a eutectic film on the grain boundaries. As defined for the binary 2219 alloy, this results in narrow brittle bands surrounding a softer solute depleted grain. Further, from the fusion boundary, the temperature will decrease. Around the eutectic temperature, the volume fraction of the ternary eutectic forming along grain boundaries will reduce and a greater amount of $\mathrm{Cu}$ and $\mathrm{Mg}$ will be retained in solid solution with a corresponding increase in hardness and hardness uniformity.

\section{Conclusions}

A method of controlling weld chemistry utilising multiple filler wires has been explored. The following findings are notable:

1. Mixed wire systems using two and three fillers are a quick and cost effective experimental method of varying and controlling weld chemistry.

2. The requirement to control the principal weld elements to suppress solidification cracking when welding $\mathrm{Al}-\mathrm{Cu}-\mathrm{Mg}$ alloys has been further validated.

3. As joint strength appears limited by the properties of the PMZ, a greater understanding of the formation of this zone is required.

4. A prototype filler wire could be made from the parent material $(\mathrm{Al}-4 \cdot 5 \mathrm{Cu}-1 \cdot 5 \mathrm{Mg})$, this composition offering acceptable mechanical properties.

5. A prototype filler would allow greater weld parameter optimisation, which could be used in a more elaborate test framework.

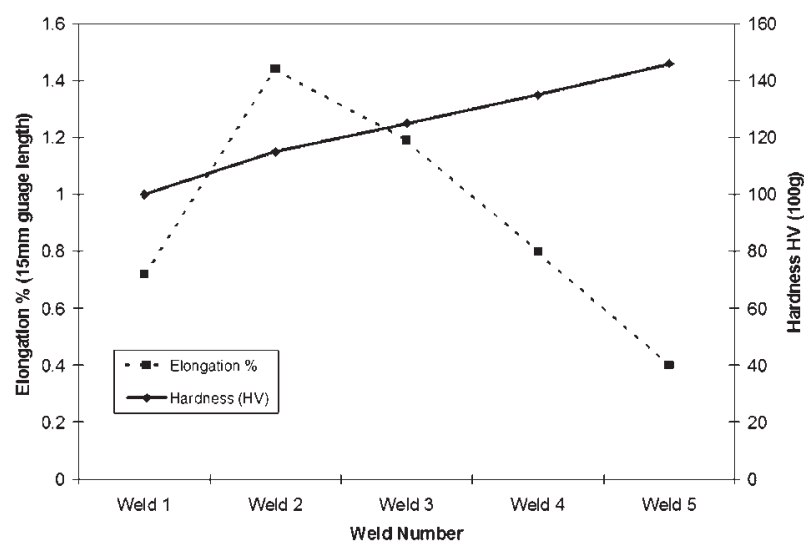

8 Comparative weld hardness and weld elongation

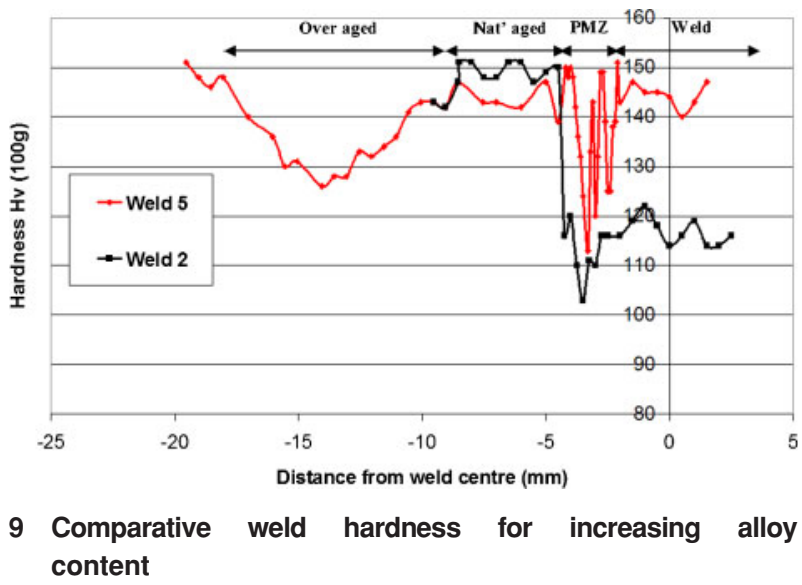

6. Additionally, mixed wire welding has potential in additive layer manufacturing applications.

\section{Acknowledgements}

This work has been conducted as part of the EPSRC/ IMRC sponsored project, Future of Advanced Aluminium Armour (Fuse $-\mathrm{A}^{3}$ ) with funding from the DSTL Joint Academic Research Programme for Defence. The authors additionally acknowledge the work of Andrew Norman for the initial thermodynamic modelling development.

\section{References}

1. G. Campbell and T. Stotler: 'Friction stir welding of armour grade aluminium plate', Weld. J.., 1999, 78, (12), 45-48. 
2. R. Mishra and Z. Ma: 'Friction stir welding and processing', Mater. Sci. Eng. Rep., 2005, 50, (1-2), 1-78.

3. C. G. Rhodes, M. W. Mahoney and W. H. Bingel: 'Effects of friction stir welding on microstructure of 7075 aluminium', Scr. Mater., 1997, 36, (1), 69-75.

4. M. Ericsson and R. Sandstrom: 'Influence of welding speed on fatigue of friction stir welding, and comparison with MIG and TIG', Int. J. Fatigue, 25, (12), 1379-1387.

5. S. Kou: 'Welding metallurgy', 2nd edn, 263-299; 2002, New York, John Wiley \& Sons.

6. T. W. Nelson, J. C. Lippold, W. Lin and W. A. Baeslack: 'Evaluation of the circular patch test for assessing weld solidification cracking', Weld. J., 1997, 76, (3), 110s-119s.

7. J. E. Steenbergen and H. R. Thornton: 'Quantitative determination of the conditions for hot cracking during welding for aluminum alloys', Weld. J., 1970, 49, (2), 61s-68s.

8. C. Huang and S. Kou: 'Liquation mechanisms in multicomponent aluminium alloys during welding', Weld. J., 2002, 81, (10), 211s$222 \mathrm{~s}$.

9. H. W. Kerr and M. Katoh: 'Investigation of heat-affected zone cracking of GMA welds of Al-Mg-Si alloys using the Varestraint test', Weld. J., 1987, 66, (9), 251s-259s.
10. M. Miyazaki, K. Nishio, M. Katoh, S. Mukae and H. W. Kerr: 'Quantitative investigation of heat-affected zone cracking in aluminum alloy 6061', Weld. J., 1990, 69, (9), 362s-371s

11. N. F. Gittos and M. H. Scott: 'Heat affected zone cracking of AlMg-Si alloys', Weld. J., 1981, 60, (6), 95s-103s.

12. G. Cao and S. Kou: 'Predicting and reducing liquation-cracking susceptibility based on temperature vs. fraction solid', Weld. J., 2006, 85, (1), 9s-18s.

13. C. Huang and S. Kou: 'Liquation cracking in full-penetration Al$\mathrm{Cu}$ welds', Weld. J., 2004, 83, (2), 50s-58s.

14. G. Mathers: 'The welding of aluminium and its alloys', 49; 2002, Boca Raton, FL, CRC Press.

15. A. Norman, K. Hyde, S. Birley and P. Pragnell: 'Examination of the effect of scandium on 2000 and 7000 series aluminium alloy castings for improvements in fusion welding', Mater. Sci. Eng. A, 2003, A354, 235-245.

16. C. Pickin, S. Williams, P. Prangnell, J. Robson and M. Lunt 'Control of weld composition when welding high strength aluminium alloy using the tandem process', Sci. Technol. Weld. Join., 2009, 14, (8), 734-739.

17. C. Huang and S. Kou: 'Partially melted zone aluminium welds: liquation mechanisms and directional solidification', Weld. J., 2000, 79, (5), 113s-120s 